\title{
Overview of E-learning Platforms for Teaching and Learning
}

\author{
https://doi.org/10.3991/ijes.v9i1.21111 \\ Mohammed Ouadoud $(\bowtie)$ \\ Abdelmalek Essaadi University, Tetouan, Morocco \\ mohammed. ouadoudegmail.com \\ Nouha Rida \\ Mohammed V University, Rabat, Morocco \\ Tarik Chafiq \\ University Hassan II, Casablanca, Morocco
}

\begin{abstract}
Distance learning experiments have been launched since 2010 in several Moroccan universities as part of an experimental approach. It, therefore, seems to us that a strategy must be put in place to give this choice of education its place in training and grant it the means necessary to achieve these objectives. The objective of this article, on the one hand, presented the typologies of elearning systems, the e-learning platforms, and the standardization in the elearning field. And the other hand, present an overview of free and proprietary e-learning platforms for teaching and learning, their functional architectures, as well as the types of e-learning devices that can be created from these online learning platforms.
\end{abstract}

Keywords - E-learning platform, learning management system, evaluation approach of the LMSs

\section{Introduction}

E-learning is a fast and efficient way of providing and sharing knowledge with learners in different parts of the world. According to [5, 6], it is defined as the following: "E-learning uses the Internet or other digital content for learning and education activities, that takes full advantage of modern educational technology to provide a new mechanism for communication and learning environment rich in resources to achieve a new way of learning."

In the 20th century, there was an international movement in favor of e-learning integration in higher education. This movement has been operationalized due to the variety of the educational offer by universities, which most have opted to diversify knowledge dissemination means (sounds, images, animations, etc.) to meet the needs of their target public. If access to knowledge was previously conditioned by the physical presence in the classroom, technology enables its learners to exceed this condition 
of presence and be opened towards other learning modalities today. We can say that e-learning brings solutions within the distance learning framework without pretending to represent the panacea for all pedagogical dysfunctions. Among these solutions, distance learning seems to be the challenge ahead to face the new training requirements in the digital era.

In the case of our study, the e-learning solutions that interest us are free e-learning platforms, because their costs, their states of development, their directions, and used technologies rendered them very close to the axis of this research.

If e-learning has many advantages in training, it cannot be said that its use sometimes poses certain problems.

Among these problems, we can point out the reluctance of teachers towards this new approach to academic and professional training. The change in habits indeed requires time to settle in. Bringing people to adapt to the journeys of change requires taking up this problem of integrating e-learning into training by university teachers.

Furthermore, an Indonesian study aimed to explore the effectiveness of e-learning usage in the classroom teaching process to promote students' critical thinking ability at the Institute IKIP Mataram [34]. Another work is mainly based on the prototyping of disciplinary information space for a new LMS. This work is first to think about the conditions for creating a real smart LMS between learners and teachers [33].

Therefore, we conducted a further analytical study on free e-learning platforms. This is based on an approach to assess their quality [31, 32, 24].

\section{E-Learning}

For several years, information and communication technologies (ICT) have been not only a new tool, a new medium, but also a means of opening up resources from around the world. ICT can be considered the result of the convergence of three technologies: IT, telecommunications, and audiovisual, these three fields are associated with the connected computer. The Internet has made this convergence a reality today.

We are thus faced with a new mode of communication which, by the quantity of information which it makes available and the variety of its sources, poses problems with considerable educational stakes in parallel to the certain advantages which it provides at all levels.

We hear about distance learning, online training, e-learning, distance education. It's a whole multitude of terms with similar apparent meaning, but which refers to different aspects of new educational technology to the fashion, and that should be distinguished.

\subsection{Definitions}

The most possible and most current distance learning is currently based on the Internet. For this, the term E-learning is increasingly used to include any open and distance learning using information and communication technologies. We adopt this term as moreover in the rest of this book. 
- E-learning: This means "electronic education"; it is a discipline where teaching theory and computer network technologies are combined to allow learners to complete their courses via a computer network (Internet or Intranet) [29].

- Distance learning: A more general concept in the sense that the means used to communicate between learners and trainers are not specified. Traditional correspondence training, communication by telephone, fax, etc. can be part of distance learning. We will note the linguistic nuance between the terms "teaching" and "training", the first evokes a longer duration and the compulsory sanction by a diploma while the second can mean a simple improvement of knowledge as is the case for training staff of companies. We also speak of $\mathrm{ODL}^{1}$ for open and distance learning; the opening is made to a large audience. The most used opening tool today remains the Web.

- Tele-education or tele-training: The use of telecommunication means it is more important in this case (telephone, fax, Internet)

- E-learning platform: is software that supports the conduct of distance learning. This type of software brings together the tools necessary for the three main users teacher, student, administrator - of a device, which aims at the remote consultation of educational contents, the individualization of learning, and tele-tutoring [12]. These systems aim to put online comprehensive lessons where the student can prepare his contrives, his license, his baccalaureate via these platforms.

\subsection{Typologies of e-learning systems}

Moving from the implementation of "face-to-face" training to the development of e-learning requires cultural, organizational, and educational changes. The relationships between trainees, content, and trainers are disrupted, making this development delicate.

In fact, according to the needs of each learning situation (target audience, type of training, area of training, etc.), we should end up with multiple systems articulating in varying proportions remote working time, time of self-study work, and face-to-face working times to adapt to the educational process and approach. Several categorizations have been proposed for e-learning systems ranging from the most global to the most detailed. The most general classification offers two categories [29]:

- Synchronous systems define a "virtual classroom" where communication between distance learning players is in real-time using sound, video, or chat

- Asynchronous systems where the student is not necessarily online with the teacher, he can work in offline mode and communicate at scheduled times or on-demand. The necessary and most used mode of communication in this kind of system is electronic mail.

1 ODL: Open and Distance Learning 
- Training with tutored and synchronized self-learning: This type of training combines remote work at a given time and face-to-face work. The device combines self-learning at a distance (a tool and its concepts for example) with a common "reformulation" and an appropriation in the classroom. Self-learning is based on different activities based on documents of different natures (reading, guided handling, exercises) described in a standardized guide sheet for the whole training, all available for download from the training site. This self-learning takes place over a day identified in the timetable of the trainees containing compulsory contacts with the trainers by sending documents, replies to questionnaires or productions. Trainers and tutors, present remotely, can be reached during this period at any time by various means (telephone, messaging, etc.) to resolve any difficulties.

- Training with tutored and desynchronized self-learning: In this type of training is found all the principles of the previous type. The difference lies in the desynchronization of the distance. In this case, the work to be done remotely takes place within a given period with a deadline. Contact with trainers and tutors still exists, but the answers to the questions are not immediate.

- Self-training: This device is based on tools integrating the entire learning process, from initiation to assessment without resorting to face-to-face. It is necessarily desynchronized and the use of the tutor is limited since the tool should in principle guide the learner as well as possible.

- Cooperative production: The distancing of trainees, if it individualizes their training, isolates them at the same time. However, group work remains a learning device, which must continue within the framework of these new methods. The setting up, for example, of cooperative productions by precise specifications, generates a dialogue and a confrontation between the different members of a group thus restoring the interactivity between them. The trainers follow the progress of the work by observing the development of production and reacting to it. All of the players are therefore involved in the work. This modality probably requires the greatest inventiveness on the part of the trainers.

- Alternating training tutored the use of remote communication tools to help develop learning by action, at the place of action, and by the specificity of the work-study program. Organized around work to be carried out in establishments, based on theoretical contributions in face-to-face or online and the use of an electronic logbook. Each trainee has a referent trainer-tutor who follows the progress of the work through this logbook and the delivery of the requested productions. The tutor can be asked by the trainee any questions he has about his work.

- Autonomous work: The concept of autonomy naturally exists in the different types of situations listed above. However, it is possible to identify forms of work that do not require the presence of trainees at the training site. For example, the reading, document, and information gathering phases, clearly identified in the training devices and the schedule are not subject to face-to-face. They thus allow trainees to broaden their research possibilities by using personal, local, academic resources, whether documentary, material, or human. 


\subsection{E-learning platforms}

The development of an e-learning platform poses the constraints relating to the development of websites but also presents certain specificities coming from its use for learning. The main considerations are:

- On the technical level: They relate mainly to computer and communication hardware and software such as the hardware and operating system of platform users and at the server level, multimedia tools, Internet connection (type, speed, etc.), download, and messaging tools.

- On the pedagogical level: They consist of taking into account the distance of the teacher and possibly the pedagogical place on the one hand and the individuality of the training on the other hand, and define the pedagogical contents and the standard courses so that the platform has interest and motivation. It is also within this framework that we define the modules, lessons, and envisaged courses.

- On the administrative level: They relate to the management of learners' schooling (registration, transcript of marks, etc.), the management of trainers (recruitment, remuneration, etc.), assignment of learners to groups, assignment of trainers to groups, etc.

- Modeling Considerations: This is the engineering of e-learning systems. At this level, models are chosen for the acquisition and representation of knowledge as well as the design of interfaces to facilitate interoperability with other systems related to the platform, the reusability of modules, adapting to changes in the platform environment.

The structure of an e-learning platform essentially comprises three actors: the learner, the teacher, and the administrator of the platform. The role of a teacher can be subdivided into teacher-designer, teacher-trainer (or teacher-tutor), teacher-corrector, etc. We also find the administrator of educational materials and administrator of schooling as a subdivision for the role of administrator. Each role is assigned specific modules for its management. The main features of a platform are:

- Creation of courses, tests, and standard courses.

- Management of educational documents (indexing, classification, updates, etc.).

- Management of a cooperative workspace between learners and / or teachers.

- Monitoring of the learner's learning and evaluation.

- Management of the learner's education.

- Provision of work tools to the learner (specific editors, download tools, T.P simulation tools, etc.).

- Making available to the various actors of communications tools and the procedures for their management (forums, messaging, chat, videoconferencing, etc.).

There are a large number of distance learning platforms on the international market, around more than 600 including around forty under free licenses. Among the 
platforms under a free license (or GPL ${ }^{2}$ license), we can cite Claroline ${ }^{3}, G^{5}$ anesha $^{4}$, and Moodle ${ }^{5}$, etc.

There are also proprietary licensed platforms such as E-doceo ${ }^{6}$, MyTeacher ${ }^{7}$, Blackboard $^{8}$ (new name since 2006 of WEBCT, etc.

\subsection{Standardization in the e-learning field}

Standardization work in the field of educational technologies is mainly linked to the work of the following organizations: IEEE ${ }^{9}, \mathrm{IMS}^{10}$, and ARIADNE, $\mathrm{ADL}^{11}$, $\mathrm{AICC}^{12}$, and $\mathrm{W}_{3} \mathrm{C}^{13}$. Two features are subject to standardization:

- Importing and integrating external educational resources into a platform.

- The reuse of courses and materials from one platform to another.

We will note the difference with general standardization work on Internet technologies (carried out by W3C) because this work will have an essential impact on the standardization of educational technologies; this is the case for standards and protocols such as:

- XML, a general standard for structuring and exchanging documents on the Web.

- WebDav, collaborative creation protocol for Web pages.

- SMIL, the standard for structuring multimedia documents.

- CSS, standard defining style sheets for HTML documents.

Likewise, the .Net strategy launched by Microsoft in July 2000, which consists of using a set of a protocol called SOAP (Simple Object Access Protocol) which defines how applications can communicate on a network, will influence the standardization processes of educational technologies.

\footnotetext{
${ }^{2}$ GPL: General Public License

${ }^{3}$ Claroline: https://www.claroline.net/

${ }^{4}$ Ganesha: http://www.ganesha.fr/

${ }^{5}$ Moodle: http://moodle.org/

${ }^{6}$ E-doceo: http://www.e-doceo.net/

${ }^{7}$ MyTeacher: https://www.cerfi.ch/

${ }^{8}$ Blackboard: http://www.blackboard.com

${ }^{9}$ IEEE: Institute of Electrical and Electronics Engineers

${ }^{10}$ IMS: Instructional Management Systems

${ }^{11}$ ADL: Advanced Distributed Learning

${ }^{12}$ AICC: Aviation Industry CBT Committee

${ }^{13}$ W3C: World Wide Web Consortium
} 
Standardization in the field of educational technologies has been coordinated since 1998 by the IEEE LTSC ${ }^{14}$. This Committee for the development of standards in the field of educational technologies has established an action program aimed at promoting standards, good practices, and practical guides facilitating the development, maintenance, and interoperability of computer applications relating to education and training.

The LTSC has set up a structure, which includes 20 working groups interested in different themes such as:

- Architecture and vocabulary.

- Questions of interest to learners (learner model, task model, identification of learners, etc.).

- Questions relating to the content (interoperability languages, internal course organization model, etc.).

- Signage and documentation of educational objects (materials, courses, etc.).

- Management platforms and systems.

Among the educational technology standardization projects, we can cite:

Instructional Management Systems: IMS, which is supported by the Educause group (of American origin) and which brings together a large number of companies in the IT sector, the multimedia training sector, the training organizations, and educational institutions, companies in general, and administrations (more than 160). IMS was launched in 1994 and aims to develop standards in the following areas:

- Description of educational materials (cataloged as metadata) to make possible publication and research on the Web (and on any information system).

- Interoperability of these materials.

- Interoperability of platforms with materials and general information systems of educational establishments for exchanging information.

- Recording of information on students (diplomas, skills, etc.).

- Exchange data between administration systems.

${ }^{14}$ LTSC: Learning Technology Standards Committee 


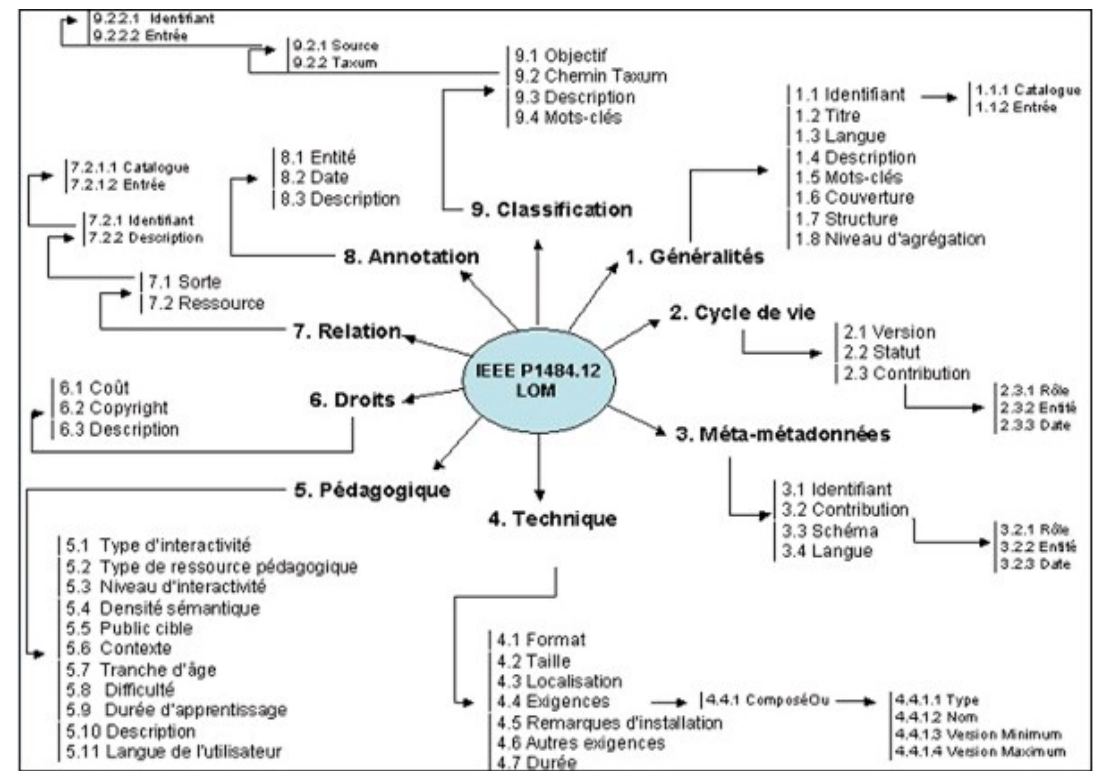

Fig. 1. The hierarchical structure of the LOM [11]

IMS has led to the $\mathrm{LOM}^{15}$ standard. Figure 1 shows the main specifications proposed by this standard.

There are adaptations of the LOM such as LOMFR proposed in 2006 by the CN36 group of AFNOR. LOMFR slightly modifies the LOM specification by notably adding four elements to the general category:

- Resource reference date (date of a particular event on the resource: modification, publication, etc.).

- Type of documentary (text, dynamic resource, etc.).

- Induced activity (briefly describes the activity that will use the resource: creating, leading, self-training, etc.)

- Validation of acquired knowledge (allows you to express the quantity of teaching or credit unit obtained after having reached educational objectives).

LOMFR induces the concept of validation of acquired knowledge to inform the result of the use of the resource, but we do not know the criteria of the evaluation method to obtain this result.

${ }^{15}$ LOM: Learning Object Metadata 
Shareable Course Object Reference Model: $\mathrm{SCORM}^{16}$ is also a standard developed at the initiative of the United States Department of Defense. It is part of the spectrum of IMS work. SCORM tries to solve three problems:

- Transferring a course, including student information, from one platform to another.

- The creation of "granular" materials used in different courses.

- Computerized research (in databases, on the Internet) of training materials and documents.

The means envisaged are the standardization of the description of the materials and the standardization of the exchange functionalities on the networks of these materials. In October 2000, the following were defined within the framework of SCORM:

- Specifications to represent the structure of a course.

- Specifications relating to the launch of applications supporting these courses.

- "Meta-data", document description items.

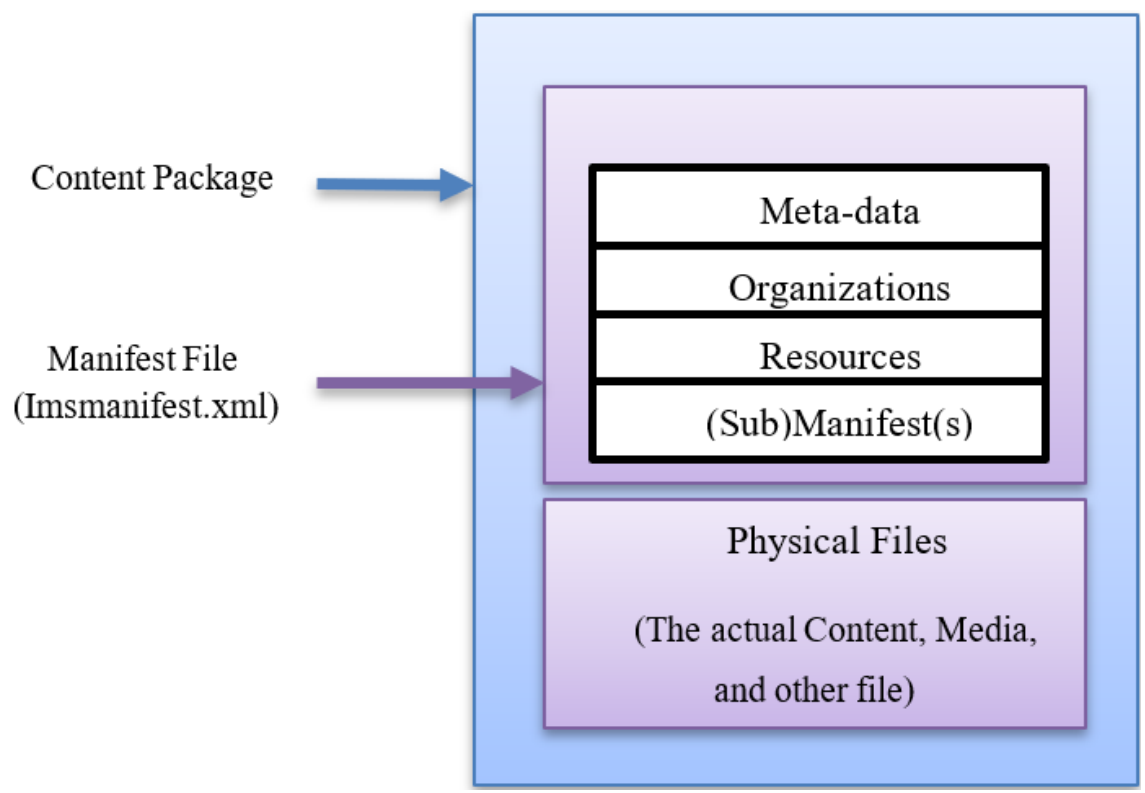

Fig. 2. Conceptual diagram of a package [9]

The techniques used are those of XML standardization (insertion of labels in documents).

${ }^{16}$ SCORM: The SCORM ${ }^{\circledR}$ (Sharable Content Object Reference Model) was created to address these interoperability, reusability, and durability challenges. As a reference model, it was intentionally designed to leverage standard web technologies as well as existing learning technology specifications that already existed. 
Today, various platforms such as Moodle, Claroline, etc. run SCORM-type resources in the form of packages. Content is packaged to make educational resources available to the learner, $\mathrm{LMS}^{17}$, and content creators. It is a standard means (per IMS specifications) for structuring and exchanging educational content between different systems and tools, i.e., it allows the transfer of educational content between the LMSs, the development tools, and the content bases.

The Content Package is represented by a compressed file in ZIP format, consisting of two main components (see Figure 2):

- A file in XML format describing the structure of the content and the association of the content with the resources. This file is called imsmanifest.xml and is located at the root of the package.

- The physical files constituting the Content Package.

Instructional Management Systems - Learning Design: We can also cite the IMS-LD specification, resulting from the work of the Open University of the Netherlands on educational modeling languages called $\mathrm{EML}^{18}$, which is a metalanguage for describing pedagogical models or scenarios (accompanied by resources and services required to achieve one or more learning objectives).

Instructional Management Systems - Question and Test Interoperability: The QTI specification of IMS allows us to represent the data structure of a question (item) and a test (assessment), as well as the corresponding results particularly, attracted our attention given the interest of this thesis for evaluation. However, as shown in Figure 3 which shows the main elements of version V2.1, this specification is based on tests and therefore questionnaires and does not deal with open questions.

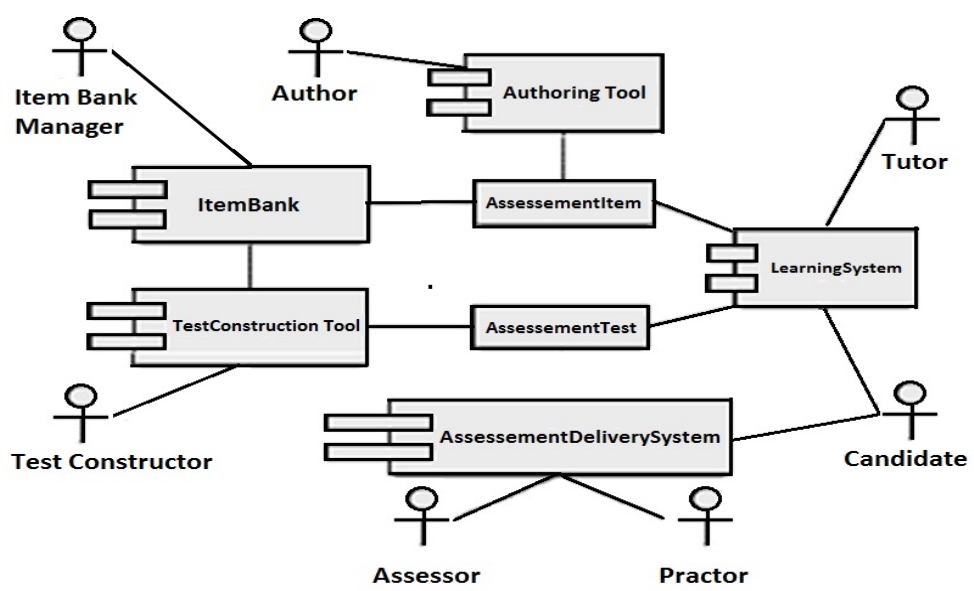

Fig. 3. Different roles of IMS QTI components [10]

\footnotetext{
${ }^{17}$ LMS: Learning Management System.

${ }^{18}$ EML: Educational Modeling Languages
} 
Synthesis: Standardization in the field of educational technologies and the Internet has an obvious effect on the engineering of learning systems. Indeed, the possibility of interoperability and the existence of a metadata bank will lighten the development of this kind of system and will facilitate their updating to adapt them to new parameters. Only, these standards must cover all the functionalities of learning and a uniform level of granularity that can meet the expectations of each designer. Their use by using adequate software tools will accelerate the production of courses with possible questionnaires. However, if we want to work on the knowledge of a teaching field with more dynamic and more "intelligent" processes as is the case of the evaluation of the learner progression in the learning of a field when there are open questions (without predefined answers) or the appropriate generation of content, we quickly notice the limitations of these standards. This is mainly because the standards cannot model the semantics of a domain, which would allow automatic processing of the represented components, which are in the majority of the cases educational resources.

\section{Free and Proprietary E-Learning Platforms}

Proprietary e-learning platforms are developed for the commercial activity of selling a distance-learning product (e.g., Captera, Training Industry, eLearning Industry, Coursera .

Free e-learning platforms are offered in open code and are based on the philosophy of "free software" defined by the "Free software Foundation" which considers free software available in the form of source code, freely reusable and modifiable (see figure 4). However, free software does not mean free because professionalism and the quality of services require the expertise and costs associated with this quality.

Proprietary e-learning platforms have certain differences from free e-learning platforms. The first important difference concerns the educational approach.

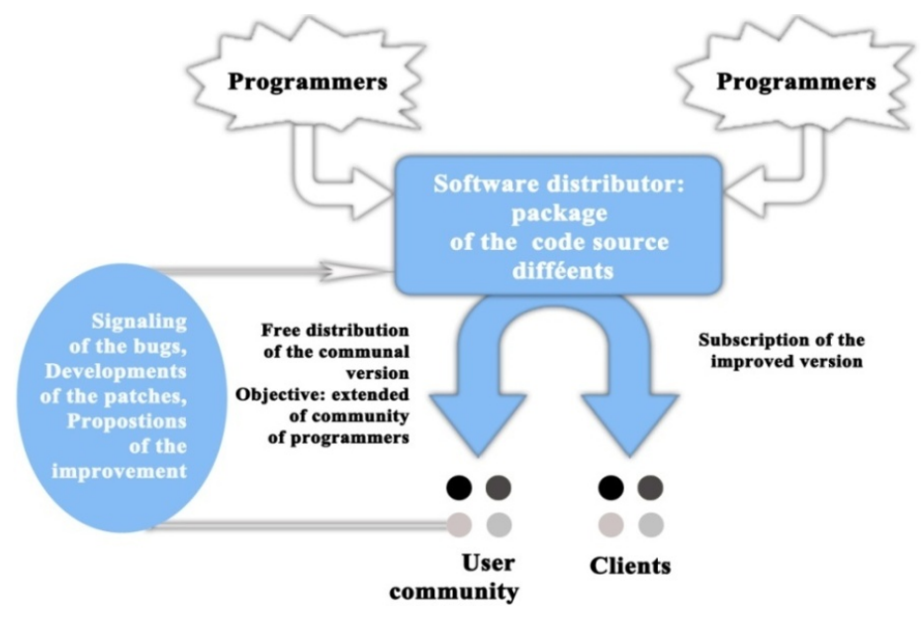

Fig. 4. Principle of Open Source 


\subsection{Social constructivism pedagogical paradigm}

Traditional teaching is often criticized for being too centered on the teacher, therefore for being unidirectional since the student has only a passive role, which consists of capturing information and memorizing it while the teacher is considered the expert who transmits knowledge.

In contrast, social constructivism ${ }^{19}$, which is a sociological theory of knowledge developed by Berger and Luckhman [1], places the student and not the teacher, at the center of the learning process. And stipulates that knowledge must be built collectively between the teacher, the student, the group of courses, the professionals and specialists in learning, the social environment such as the family and the community (hence the name of social constructivism). The learning links are therefore bidirectional and multidirectional as illustrated in Figure 5.

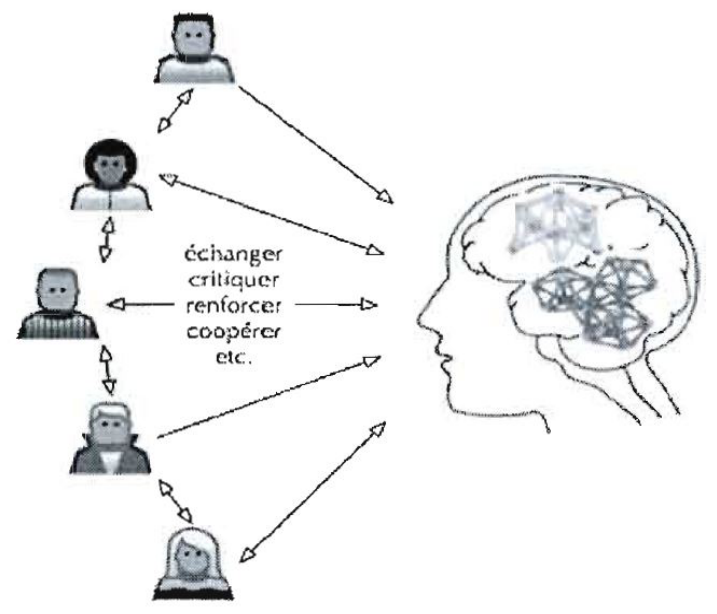

Fig. 5. Learning in society: socio-constructivism $[7,1]$

As a result, even if the knowledge is personal, it is carried out in a social framework, which brings benefits in the sense that the information comes not only from what one thinks but also from social interactions with many other social workers (see Figure 6).

${ }^{19}$ Social constructivism: is centered on the learner. The learner learns through its representations. The construction of knowledge although personal is carried out in a social setting. The context and come from both what we think and what others bring as interactions. 


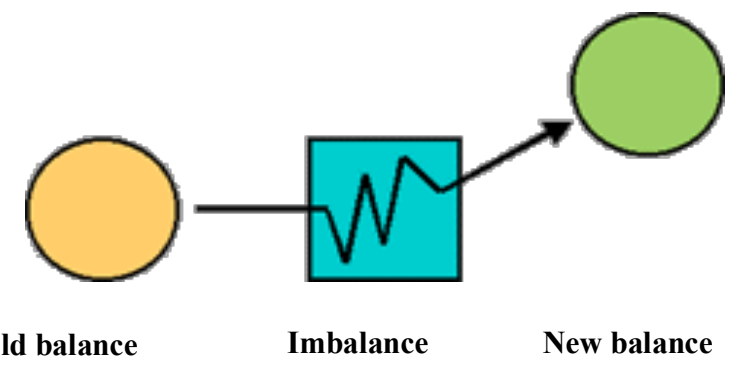

Fig. 6. The Social constructivist model [1]

The imbalance is a disturbing element, which requires an effort of understanding to pass to a higher level of knowledge. In this new paradigm, educational contents are no longer at the center of the learning process, what matters is the richness of social interactions that allow knowledge sharing as illustrated in figure 6. This modern learning philosophy is, therefore, more than a form of distance learning because it not only motivates students. This latter, who now plays an active role by transmitting their knowledge, but also allows the teacher to have personalized contacts adapted to the needs of each student and to animate the discussions and the activities to achieve the common objectives of the class. Technologically, Open-Source learning platforms allow this kind of pedagogical approach, as evidenced by the approach of Martin Dougamias, designer of Moodle, which is based on this social constructivist pedagogy, which places the user, and not the platform, at the learning center. The PLUME $^{20}$ university team, which has set up a platform in France inspired by this learning philosophy, even asserts about traditional platforms that more than $70 \%$ of devices fail due to poor needs analysis, but also due to the wear and tear that users experience when faced with the virtuality of the platform. All these seven exchanges on the Web must be supported by exchanges between humans and not between humans and platforms, because of weariness, discouragement then failure [4].

The emphasis on social interactions explains why Moodle now benefits from a large international community of members, an annual conference of users who are no longer just professional developers but also ordinary users, documentation online developed in wiki media and translated into 85 languages around the world, and finally interactive multimedia services to better understand the pedagogy of the platform.

\subsection{IT environment}

Among the technological and functional advantages of open-source platforms, which differentiate them from proprietary platforms, we can cite the following aspects:

${ }^{20}$ PLUME: Promoting Useful, Controlled and Economic Software 
Standardization, normalization, and interoperability: An important aspect of functionality is that of interoperability, which is very limited in proprietary environments when it is a fundamental requirement for developers of free and open-source software. Compliance with standards guarantees good interoperability with other software. Since the sources are open, there is no point in using incompatible protocols or non-standard file formats. The standardization of data also makes it possible to reuse it by other software in a reliable manner and at a lower cost.

As a result, standardization not only ensures an improvement in the educational efficiency of software products but also a better economic efficiency of investments in online training. In his study on the standardization of online training, Simard [8] presents the main attributes of this standardization, which have been grouped in Table 1.

These attributes are considered by the author as advantages because they are not found, or only partially, in environments that do not conform, or hardly conform, to norms (jury recognition) or standards (de facto recognition only).

We will not discuss in the brief how-to standardize e-learning because it is a vast and very complex subject that does not fit into the objectives of our research which were defined when the brief was introduced.

If we go from generic standards relating to all aspects of software quality (e.g., ISO $9126[25,26,27,28]$ to specific standards relating to a particular aspect such as interoperability with its standards like SCORM and IMS specific to e-learning. We can cite a study carried out for Sun Micro-System and in which the authors' Collier and Robson [3] describe well the advantages of interoperability standards for all stakeholders.

For the software system purchaser, the main advantage is the non-dependence on the manufacturers of these systems. For the latter and their designers, the work and therefore the cost of designing interfaces is reduced because it is no longer necessary to develop interfaces specific to each software product, as in the proprietary approach. As a result, the manufacturer achieves significant economies of scale when demand increases. Finally, for the user, interoperability standards allow them to access and share the contents of a wide variety of educational resources.

Table 1. Benefits of standardizing e-learning [8]

\begin{tabular}{|l|l|}
\hline \multicolumn{1}{|c|}{ Criteria } & \multicolumn{1}{c|}{ Description } \\
\hline Accessibility & $\begin{array}{l}\text { Enable research, identification, access, and delivery of online training content and } \\
\text { components in a distributed manner. }\end{array}$ \\
\hline Interoperability & $\begin{array}{l}\text { Allow the use of content and components developed by an organization on a } \\
\text { given platform by other organizations on other platforms; }\end{array}$ \\
\hline Reusability & $\begin{array}{l}\text { Allow the reuse of contents and components for different purposes, in different } \\
\text { applications, in different products, in different contexts, and different modes of } \\
\text { access. }\end{array}$ \\
\hline Durability & $\begin{array}{l}\text { Allow the contents and components to face technological changes without the } \\
\text { need for reengineering or redevelopment. }\end{array}$ \\
\hline Maintainability & The ability to support the constant evolution of pedagogical content at a low cost. \\
\hline Adaptability & Allow tailor-made modulation of contents and components \\
\hline
\end{tabular}


Efficiency, reliability, and reusability: The availability of source codes allows users not only to consult them but also to modify them. Consequently, experienced developers can resolve errors located in code quickly. This ensures free software better efficiency compared to proprietary software whose design flaws are not quickly modified because their publishers often have the habit of not fixing these flaws until the release of a new version of their software. Besides, this efficiency is also accompanied by good reliability because, as the popular jargon says about free software: "With enough eyes to watch, bugs can no longer hide" [1].

Free software development is a process to which a large community of developers and publishers, spread across the world, contributes. This development process is effective because it allows, therefore, considering several technical solutions, the best of which are selected by a natural selection process. The development process is not only effective but it is also profitable because the reuse of the code is an important source of saving time and therefore money.

For all these advantages, free software is often considered free or is bought at a relatively modest price compared to the high purchase costs of proprietary software such as Captera, Training Industry, eLearning Industry, Coursera... However, free software publishers generally offer service contracts associated with their products to give professional guarantees to their customers who have the freedom to subscribe or not according to the needs and the IT resource management policy of each of them. Free software is therefore not free software. However, the relatively low acquisition costs, thanks to the availability of source code for a very large number of users, and less dependence on suppliers are added to reduce operating costs thanks to the adoption of interoperability standards and the sharing of reusable educational objects.

\section{$4 \quad$ Teaching and Learning Systems}

It is a coherent whole made up of resources (material and human), strategies, methods, and actors interacting in a given context to achieve a goal " [21]. He specifies that: "The learning device aims to allow someone to learn something with the technological tool.

We propose to integrate the role of the teacher in the learning device. Research in CEHL21 studies the means of assisting the learner and to those who favor this learning (teacher, trainer, tutor, peers, etc.).

In national and international research in EIAH, there are already many types of personalized devices from LMSs or LCMSs such as Moodle, Claroline, ATutor, and Sakai where the courses are online and open. These devices are developed within the framework of DE, face-to-face training, and open training. They are called Virtual Campuses. Online University. Virtual Universities namely:

${ }^{21}$ CEHL: Computer Environments for Human Learning 
- MOOC (Massive Open Online Course)

- PLE (Personal Learning Environment)

- VLE (Virtual Learning Environment)

- C3MS (Community, Content, \& Collaboration Management Systems)

\subsection{Massive open online course}

Massive Open Online Course. MOOCs are open online courses that bring together a large number of students. They have not failed to interest many economic and political actors who see in them a successor to e-learning or distance learning devices to train a large number of people.

Table 2. Comparison between cMOOCs and xMOOCs

\begin{tabular}{|c|c|c|}
\hline $\begin{array}{l}\text { Comparison of } \\
\text { MOOCs }\end{array}$ & cMOOCs & xMOOCs \\
\hline Learning outcomes & $\begin{array}{l}\text { Develop digital, social, and intellectual skills } \\
\text { associated with the web. "Choose an answer" }\end{array}$ & Acquire knowledge. "Find an answer" \\
\hline Thematic & $\begin{array}{l}\text { Open and forward-looking, knowledge is to } \\
\text { be built through experience, the debate of } \\
\text { ideas, analysis, model identification. }\end{array}$ & $\begin{array}{l}\text { Elementary or at least thematic where } \\
\text { knowledge is formalized, stable, delim- } \\
\text { ited introductory course }\end{array}$ \\
\hline Pedagogical model & $\begin{array}{l}\text { Connectivist approach, building your learn- } \\
\text { ing by sharing and discussing with others }\end{array}$ & $\begin{array}{l}\text { Traditional approach: well-structured } \\
\text { course, the material provided, work and } \\
\text { tests, reassuring }\end{array}$ \\
\hline Target audience & Learners with digital skills prerequisites & $\begin{array}{l}\text { Larger audience, learners with fewer } \\
\text { digital skills }\end{array}$ \\
\hline
\end{tabular}

The MOOC movement was created to provide access to high-quality education in remote corners of the United States and the world [13]. MOOCs are at such an early stage of development that there is not yet an agreed or preferred way to describe their approach [14]. The latter is a model of educational provision, which is, to varying degrees:

- Massive: The course can accommodate, in principle, an unlimited number of participants, sometimes tens of thousands.

- Open: The course is open to all Internet users, regardless of origin, level of study, without institutional affiliation necessary, generally free of charge.

- Online: Comments, evaluations, conferences, Tutoring, and follow-up are carried out remotely without the obligation of presenting,

- Course: There are training programs structured around a set of learning objectives in a defined field of study. An expert or a group of experts in a particular field creates the outline of the course and facilitate a series of interactive readings and discussion forums on a given theme.

Two types of MOOCs are now commonly discussed. The first is based on the connectivism theory of learning, which promotes informal learning networks; those students co-construct the course with the teaching team. The latter is known as cMOOC. The second builds on a cohesive and organized set of resources, known, as XMOOC 
which is more traditional, content-based, and much more like traditional educational models. Depending on the content, xMOOC is more likely to have one or more speakers, usually by broadcasting conferences via YouTube-style videos, with tasks and discussions online via proprietary software. This organization allows the university to integrate the MOOC into existing programs. Deadlines for completing tasks and a form of continuous online assessment allow course administrators to assign brands and credits. Online participants who are not interested in obtaining credits may or may not participate as they wish.

\subsection{Personal learning environment}

PLE is a system, a set of tools, or an ecosystem, which helps learners to build and organize their learning. Personal learning is learning in which the learner controls his learning process, his environment, the resources he has access to, and the people with whom he interacts.

Personal learning environments as an idea that first integrates "pressures and movements" such as lifelong learning, informal learning, learning styles, new approaches to assessment, cognitive tools. Also, the PLEs are inspired by the success of new "sticky" technologies in ubiquitous computing and social software [16].

There is no consensus on the definition of a personal learning environment. Broadly speaking, Graham presents it as "a new approach to the use of technologies to learn" [15]. According to Nicolas Roland, a researcher in education science, it is "an ecosystem of people and tools that the individual mobilizes, and organizes within the framework of knowledge-building activities" [22]. This means a centralized learning environment, unlike the LMSs. Some authors (Terry Anderson, Ron Lubensky, and Mark van Harmelen) highlight the digital aspect of the system (software, applications, web service) while others (Clive Shepherd .) add physical resources (family, friends, books, magazine, newspaper, television . In the different definitions, the same objective of a PLE appears: to build and manage your learning, to take charge. The trainer Marc Dennery summarizes the PLE as the set of tools and methods available to the learner allowing him to achieve his learning objectives" [17].

\subsection{Virtual learning environment}

A Virtual Learning Environment in educational technology is a web-based platform for the digital aspects of study courses, usually in educational institutions. VLEs generally allow participants to be organized into cohorts, groups, and roles, resources, activities, and interactions in a course structure provide the different stages of the evaluation report on participation; and have a certain level of integration with other institutional systems $[18,19]$. For those who edit them, VLEs can have a de facto role as a design architecture and design [20]. Almost all higher education institutions in the English-speaking world have adopted VLEs. Here are the main components required for a virtual learning environment or an online education program to take place: 
- Content management - Creation, storage, access, and use of learning resources.

- Mapping and planning of the study program - Course planning, evaluation, and personalization of the learning experience.

- Learner engagement and administration - Managing access to learner information and resources and monitoring progress and success.

- Communication and collaboration - Emails, reviews, chat, wikis, blogs.

\subsection{Community, Content, and Collaboration Management Systems}

C3MS, that is to say, a software based on the Web, which makes it possible to manage a community, the collaboration between the members and the contents. C3MS can refer to an existing portal that includes several generally simple modules or to a portal (i.e., the toolbox) necessary to install and configure the portal.

Simple Internet technologies (web pages, forums, email, FTP, etc.) have been successful in education because they have responded to the basic needs for information exchange, communication, and collaboration necessary for constructivist scenarios.

In addition to being simple, yet powerful, the Internet allows the user (teachers) to have control over it. While simple web technology allows for creative scenarios, it has four drawbacks:

- Maintaining static websites (including student pages) takes time

- Simple discussion systems, like forums or mailing lists, don't do very good knowledge management

- More sophisticated scenarios are poorly supported

- Moreover, there is no glue to put all these elements together.

Community websites face very similar problems and seem to have found at least a partial answer. Over the past two years, an impressive number of what the authors represent C3MS have cropped up in existence.

Inspired by personal weblogs (also called blogs, increasingly popular journaling systems), Slashdot-like weblog/information systems, simple content management systems, and various popular groupware applications, they offer a modular system for setting up interactive community websites.

Besides, most of these systems provide documented extension mechanisms allowing third parties to contribute modules with additional functionality.

C3MS systems are a form of web portals. A portal brings together a variety of useful information, and communication resources into a single web page [23]. A portal is, therefore, a collection of objects (information bricks) and services (operation on these bricks) which can be accessed from the portal page (Web).

\section{Conclusion}

When teaching in Morocco started in the e-learning era, dropout and failure rates were very high. Research on this learning has shown that learners need a personalized device and in a particular personalized follow-up. Similarly, the first observations of 
university devices indicate that around $10 \%$ of learners go until the end of the course. This type of situation covers situations that we can problematize in research. In this number of students who drop out. Therefore, providing a personalized and customizable device could help them maintain their motivation and learning.

In this perspective, a comparison between online learning devices in Morocco and those of Europe and America will be celebrations in future work.

\section{References}

[1] Benyounes, B., "Évaluation de la fonctionnalité et l'utilisabilité de la plateforme d'apprentissage Moodle : une approche du génie logiciel," Mémoire présenté comme exi-gence partielle de la maîtrise en informatique - université du Québec à Montréal, Oct-2009.

[2] Colace, F., De Santo, M., Vento M., (2003) "Evaluating Online learning platforms: a Case Study" Proceedings of the 36th Hawaii International Conference on System Sciences HICSS'03) http://csdI2.computer.org/comp/proceedings/hicss/2003/1874/05/187450154c. pdf https://doi.org/10.1109/HICSS.2003.1174342

[3] Collier G., Robby, R., (2002) SUN Microsystems, e-learning interoperability standards, by Eduworks Corporation.

[4] Dossou A., Koffi, D., Durand, A., Leproust, M., Vanderstichel (2007) "Étude comparative de plateformes de formation à distance", projet de fin d'étude, Master Ingénierie Pédagogique MultiMedia, CUEEP de Lille.

[5] Liu, C.-H., "The comparison of learning effectiveness between traditional face-to-face learn-ing and e-learning among goal-oriented users", in Digital Content, Multimedia Technology and its Applications (IDC), 2010 6th International Conference on. 2010. IEEE.

[6] Karim, F., Goodwin, R., "Using Cloud Computing in e-learning Systems," International Journal of Advanced Research in Computer Science \& Technology (IJARCST), Vol. 1 Issue 1 Oct-Dec 2013, pp.66-67.

[7] Guité, F., 2011 'Constructivisme, socioconstructivisme et connectivisme" http://www.francoisguite.com/2007/10/constructivisme-socioconstructivisme-etconnectivisme/

[8] Simard, C., (2002) "Normalisation de la formation en ligne, Enjeux, tendances et perspectives", document d'orientation stratégique, préparé pour l'Agence universitaire de la francophonie (AUF), Bureau Amérique du Nord.

[9] A. Semeteys, "Formation à distance : La norme SCORM2004," Extrait d'un ouvrage des Editions EducaWeb, 2006.

[10] Née Dahmani F., B. "Modélisation basée ontologies pour l'apprentissage interactif - Appli-cation à l'évaluation des connaissances de l'apprenant," PhD dissertation in computer science, Computer Science Department, Mouloud Mammeri University of Tizi-Ouzou, Alge-ria, 28 November, 2010.

[11] Jarraud, P., De La Passardière, B. "Un profil d'application du LOM pour Campus Sciences, " Revue STICEF, Volume 11, 2004. https://doi.org/10.3406/stice.2004.886

[12] OVAREP (Observatoire des ressources multimédias), 2000 Étude comparative technique et pédagogique des plateformes pour la formation ouverte et à distance

[13] Sonwalkar, N. (2013). The First Adaptive MOOC: A Case Study on Pedagogy Framework and Scalable Cloud Architecture-Part I. In MOOCs Forum (Vol. 1, No. P, pp. 22-29). 140 Huguenot Street, 3rd Floor New Rochelle, NY 10801 USA: Mary Ann Liebert, Inc. https://doi.org/10.1089/mooc.2013.0007 
[14] Porter, S. (2015). To MOOC or Not to MOOC: How Can Online Learning Help to Build the Future of Higher Education?

[15] Roland, N. (2013) "EPA : système ou écosystème ?" Hypomnematon.

[16] Attwell, G. (2007). "Personal Learning Environments - the future of e-learning?" elearning Papers. Vol 2, $\mathrm{N}^{\mathrm{o}}$ 1. https://issuu.com/elo-wiki/docs/informallearning

[17] Dennery, M., "Bâtir son environnement d'apprentissage personnel : la première des formations," Le blog de C-Campus, 20-Dec-2013.

[18] Britain, S., Liber, O. (1999). "A Framework for Pedagogical Evaluation of Virtual Learning Environments," JISC Technology Applications Programme (Report 41). Archived from the original (PDF) on 2014-06-14. Retrieved 1 February 2015.

[19] Weller, M. "Virtual Learning Environments: Using, Choosing and Developing your VLE," Oxford, UK: Routledge, 2007. https://doi.org/10.4324/9780203964347

[20] Masterman, L. (2013). "The challenge of teachers' design practice". Written in London. In Beetham, Helen; Sharpe, Rhona. Rethinking pedagogy in a digital age. Oxford: Routledge. p. 65.

[21] Lebrun, M. e-learning pour enseigner et apprendre : allier pédagogie et, Academia Bruylant, Louvain-la-Neuve, Belgique, 2005.

[22] Attwell, G. (2007). Personal Learning Environments for creating, consuming, remixing and sharing

[23] Looney, M., Lyman, P. (2000), "Portals in Higher Education: what are they and what is their potential", EDUCAUSE Review, Vol. 35, No. 4, July/August, pp.28-36.

[24] M. Ouadoud, M. Y. Chkouri, A. Nejjari, and K. E. El-Kadiri, "Exploring a Recommendation System of Free eLearning Platforms: Functional Architecture of the System," International Journal of Emerging Technologies in Learning (iJET), vol. 12, no 02, p. 219 226, Feb. 2017. https://doi.org/10.3991/ijet.v12i02.6381

[25] ISO/IEC 9126-1: 2001. Software Engineering -Software product quality -Part 1: Quality Model

[26] ISO/IEC 9126-2: 2003. Software Engineering -Software product quality -Part 2: External Metrics

[27] ISO/IEC 9126-3: 2003. Software Engineering -Software product quality -Part 3: Internal Metrics

[28] ISO/IEC 9126-4: 2004. Software Engineering -Software product quality -Part 4: Quality in use Metrics

[29] O'Neil, M. "What is E-learning", Home Magazine, May 2001.

[30] Charpille, J. L., Couniliufm, E. "Mettre à distance la formation", publication de l'Académie de Nancy-Metz de décembre 2001, mise en ligne d'Avril 2002.

[31] M. Ouadoud, M. Y. Chkouri, and A. Nejjari, "LeaderTICE: A Platforms Recommendation System Based on a Comparative and Evaluative Study of Free eLearning Platforms," International Journal of Online Engineering (iJOE), vol. 14, no. 01, pp. 132-161, Jan. 2018. https://doi.org/10.3991/ijoe.v14i01.7865

[32] M. Ouadoud, M. Y. Chkouri, A. Nejjari, K. E. El-Kadiri, (2016) Studying and Analyzing the Evaluation Dimensions of ELearning Platforms Relying on a Software Engineering Ap-proach. International Journal of Emerging Technologies in Learning (iJET). 2016, Vol. 11 Issue 1, p11-20. 10p. https://doi.org/10.3991/ijet.v11i01.4924

[33] M. Ouadoud, T. Marrakchi, et R. Taghzout, " Prototyping a Disciplinary Information Space for a New Smart Learning Management System Based on IMS-LD and NoSQL ", Interna-tional Journal of Recent Contributions from Engineering, Science \& IT (iJES), vol. 8, no 4, Art. no 4, Dec. 2020. https://doi.org/10.3991/ijes.v8i4.19071 
[34] S. Prayogi et N. N. S. P. Verawati, « The Effectiveness of E-Learning Usage in Classroom Teaching to Promote Critical Thinking Ability », International Journal of Recent Contributions from Engineering, Science \& IT (iJES), vol. 8, no 4, Art. no 4, Dec. 2020. https://doi.org/10.3991/ijes.v8i4.18023

\section{Authors}

Mohammed Ouadoud is a Muslim man from Morocco. He is a Ph.D. in Computer sciences, at the Laboratory of the Information System and Software Engineering (SIGL) at National School of Applied Sciences, Abdelmalek Essaâdi University. In 2018, He completed his Ph.D. thesis in computer science at the faculty of science of Tetouan, Morocco. His dissertation research focuses on Modeling and Prototyping a Learning Management System Based on the IMD-LD, the NoSQL, and the Hybridization between Learning Theories. He has a Master's degree in Multimedia Engineering of Instructional Design from the École Normale Supérieure of Martil, Morocco in 2013. His current research focuses on IT, E-learning, Public Health, and Software Engineering. He is a reviewer in several international journals.

Nouha Rida is currently a Ph.D. at Computer and Education Research Laboratory at Mohammadia School of Engineer, Mohammed V University, Morocco. She received her degree in engineering in computer science from "Ecole Nationale Superieur de Mine of Rabat". Her main research interests are related to intelligent transportation systems and road traffic optimization.

Tarik Chafiq is a part-time lecturer and scientific collaborator at Hassan II University who is specialized in the research field of geomatics such as Geographical Information Systems (GIS) analyses and Spatial Data Infrastructures (SDI). From 2016 and 2017, he had been a research scientist at Alexandru Ioan Cuza. He got his $\mathrm{Ph}$.D. degree and Master's degree in geoinformatics. More, Microsoft certified him as an expert in C\# and HTML5.

Article submitted 2021-01-13. Resubmitted 2021-02-22. Final acceptance 2021-02-24. Final version published as submitted by the authors. 